DOI: https://doi.org/10.47405/mjssh.v5i2.413

\begin{tabular}{|c|c|}
\hline 4 & Malaysian Journal of Social Sciences and Humanities (MJSSH) \\
\hline $\begin{array}{l}\text { Malaysian Journal of } \\
\text { Social sciences and }\end{array}$ & Volume 5, Issue 2, February 2020 \\
\hline (MJ-SSH) & e-ISSN : 2504-8562 \\
\hline & $\begin{array}{l}\text { Journal home page: } \\
\text { www.msocialsciences.com }\end{array}$ \\
\hline
\end{tabular}

\title{
Penggunaan Sumber Dokumen dalam Mata Pelajaran Sejarah: Peningkatan Kemahiran Pemikiran Sejarah?
}

\author{
M. Kaviza ${ }^{1}$ \\ 1Pusat Pengajian Pendidikan dan Bahasa Moden, Universiti Utara Malaysia (UUM) \\ Correspondence: M. Kaviza (kavizakaviza@yahoo.com)
}

\begin{abstract}
Abstrak
Kajian eksperimen ini bertujuan untuk mengkaji kesan penggunaan sumber dokumen terhadap peningkatan kemahiran pemikiran sejarah. Kajian ini melibatkan seramai 111 orang murid tingkatan empat. Instrumen kajian ini merupakan soal selidik kemahiran pemikiran sejarah yang diadaptasi yang telah disahkan oleh pakar penilai dan mempunyai nilai ketekalan yang baik. Data kajian ini dianalisis secara deskriptif dan inferensi iaitu ujian ANCOVA dan MANCOVA melalui perisian IBM SPSS. Dapatan kajian ini menunjukkan bahawa terdapat perbezaan yang signifikan min skor ujian pasca bagi kemahiran pemikiran sejarah dan kelima-lima konstruknya iaitu memahami kronologi, meneroka bukti, membuat interpretasi, membuat imaginasi dan membuat rasionalisasi antara kumpulan eksperimen dan kumpulan kawalan dengan mengawal skor min ujian pra. Implikasi kajian ini telah mencadangkan kepada guru-guru sejarah untuk memainkan peranan penting dalam membuat penambahbaikan terhadap proses pengajaran dan pembelajaran daripada berpusatkan guru kepada berpusatkan murid dengan matlamat untuk mengubah status mata pelajaran sejarah sebagai mata pelajaran yang menarik.
\end{abstract}

Kata kunci: sumber dokumen, mata pelajaran sejarah, kemahiran pemikiran sejarah

\section{Document Sources Use in History Subject: Improving Historical Thinking Skills?}

\begin{abstract}
This experimental study aims to examine the effect of document sources use on improving historical thinking skills. This study involved 111 form four students. This research instrument is an adapted historical thinking skills questionnaire which has been verified by expert and has a good reliability. The data of this study were analyzed descriptively and inference such as ANCOVA and MANCOVA tests using IBM SPSS software. The findings of this study indicated that there are significant mean score differences of historical thinking skills and their five constructs namely chronology understanding, evidence exploring, interpretation, imagination and rationalizing in post-test between experimental and control group by controlling pre-test mean score. The implications of this study suggested the history teachers to play an important role in improving the teaching and learning process from teacher-centered to student-centered with the aim of transforming the status of history subject as interesting.
\end{abstract}

Keywords: document sources, history subject, historical thinking skills 


\section{Pengenalan}

Mata pelajaran sejarah telah dijadikan sebagai mata pelajaran wajib lulus mulai tahun 2013 pada peringkat peperiksaan Sijil Pelajaran Malaysia (SPM) hingga kini dengan tujuan untuk meningkatkan taraf dan martabat pendidikan sejarah pada peringkat global (Mohd Samsudin \& Shahizan Shahruddin, 2012; Mohamad Rodzi Abdul Razak, 2009). Sehubungan dengan itu, Kurikulum Standard Sekolah Menengah (KSSM) telah dilaksanakan di bawah teras dua dalam Pelan Pembangunan Pendidikan Malaysia 2013-2025 dengan menekankan kepada elemen pemikiran kritis dan kreatif bagi mendorong murid-murid untuk bersaing pada peringkat antarabangsa (Pusat Perkembangan Kurikulum [PPK], 2018; Kementerian Pendidikan Malaysia [KPM], 2013). Justeru, pembaharuan dalam kurikulum Sejarah adalah diperlukan dari aspek proses penambahbaikan terhadap pendekatan, strategi dan kaedah pengajaran dan pembelajaran yang berkesan yang berpusatkan murid dengan melibatkan mereka secara aktif melalui aktiviti dan tugasan pembelajaran yang dapat mencabar proses pemikiran (KPM, 2014).

\section{Pernyataan Masalah}

Adalah diakui bahawa kaedah pengajaran dan pembelajaran yang bersifat sehala yang dilaksanakan tidak mampu untuk meningkatkan kemahiran pemikiran sejarah yang terdiri daripada konstruk memahami kronologi, meneroka bukti, membuat interpretasi, membuat imaginasi dan membuat rasionalisasi seperti yang dihasratkan dalam kurikulum sejarah (PPK, 2018). Hal ini telah mengakibatkan mata pelajaran sejarah dianggap sebagai mata pelajaran yang membosankan dan tidak disukai oleh murid-murid (Cuban, 2016; Gleeson \& D’Souza, 2016; Fitzgerald, 2009; Kobrin, 1996; Omardin Haji Ashaari \& Yunus Muhamad, 1996). Justeru, permasalahan tersebut telah menimbulkan terdapat satu keperluan untuk membuat penambahbaikan kepada kaedah pengajaran dan pembelajaran sejarah dengan menerapkan elemen penyertaan murid secara dua hala yang dapat merangsang murid berfikir. Oleh itu, penggunaan sumber dokumen seperti akhbar, majalah, enskliopedia, jurnal, risalah dan sebagainya adalah berpotensi digunakan dalam proses pengajaran dan pembelajaran sejarah bagi menggalakkan murid-muid untuk mencetus idea asli, menjalani pengalaman pembelajaran dalam konteks dunia sebenar dan membuat hubungkait kandungan sejarah dengan isu semasa (PPK, 2014; Barton, 2018; Newmann, 2001; Sandwell, 2008). Maka, kajian ini adalah bertujuan untuk mengkaji kesan penggunaan sumber dokumen terhadap peningkatan kemahiran pemikiran sejarah.

\section{Objektif Kajian}

Objektif Kajian ini adalah seperti berikut:

i. Mengenal pasti perbezaan min skor ujian pasca bagi kemahiran pemikiran sejarah bagi murid dalam kumpulan eksperimen dengan murid dalam kumpulan kawalan dengan mengawal min skor ujian pra.

ii. Mengenal pasti perbezaan min skor ujian pasca bagi kemahiran memahami kronologi, kemahiran meneroka bukti, kemahiran membuat interpretasi, kemahiran membuat imaginasi dan kemahiran membuat rasionalisasi bagi murid dalam kumpulan eksperimen dengan murid dalam kumpulan kawalan dengan mengawal min skor ujian pra.

\section{Soalan Kajian}

Soalan kajian ini adalah seperti berikut:

i. Adakah terdapat perbezaan min skor ujian pasca bagi kemahiran pemikiran sejarah bagi murid dalam kumpulan eksperimen dengan murid dalam kumpulan kawalan dengan mengawal min skor ujian pra?

ii. Adakah terdapat perbezaan min skor ujian pasca bagi kemahiran memahami kronologi, kemahiran meneroka bukti, kemahiran membuat interpretasi, kemahiran membuat imaginasi 
DOI: https://doi.org/10.47405/mjssh.v5i2.413

dan kemahiran membuat rasionalisasi bagi murid dalam kumpulan eksperimen dengan murid dalam kumpulan kawalan dengan mengawal min skor ujian pra?

\section{Hipotesis Kajian}

Hipotesis kajian $\left(\mathrm{H}_{\mathrm{o}}\right)$ ini adalah seperti berikut:

$\mathrm{H}_{\mathrm{ol}}$ : Tidak terdapat perbezaan min skor ujian pasca bagi kemahiran pemikiran sejarah yang signifikan bagi murid dalam kumpulan eksperimen dengan murid dalam kumpulan kawalan dengan mengawal min skor ujian pra.

$\mathrm{H}_{\mathrm{o} 2}$ : Tidak terdapat perbezaan min skor ujian pasca bagi kemahiran memahami kronologi, kemahiran meneroka bukti, kemahiran membuat interpretasi, kemahiran membuat imaginasi dan kemahiran membuat rasionalisasi yang signifikan bagi murid dalam kumpulan eksperimen dengan murid dalam kumpulan kawalan dengan mengawal min skor ujian pra.

\section{Metod Kajian}

Kajian eksperimen dengan reka bentuk ujian pra-ujian pasca kumpulan kawalan tidak serupa (Cook \& Campbell, 1979) ini melibatkan 111 orang murid Tingkatan Empat yang dipilih melalui teknik persampelan bertujuan-kelompok dari dua buah sekolah menengah harian. Instrumen kajian ini merupakan soal selidik kemahiran pemikiran sejarah yang diadaptasi. Instrumen kajian tersebut juga telah disahkan oleh dua orang pakar penilai serta mempunyai nilai kebolehpercayaan Cronbach Alpha iaitu 0.95 yang dianggap baik dan boleh diterima dalam kajian ini (Nunnally, 1978). Data kajian ini telah dianalisis secara deskriptif dan inferensi iaitu ujian ANCOVA dan MANCOVA melalui perisian IBM SPSS Statistic.

\section{Dapatan Kajian}

\section{Perbezaan min skor kemahiran pemikiran sejarah}

Analisis statistik deskriptif pada Jadual 1, min skor kemahiran pemikiran sejarah adalah lebih tinggi bagi kumpulan eksperimen $(M=125.05, S D=18.85)$ berbanding dengan kumpulan kawalan $(M=103.84$, $S D=21.43)$. Seterusnya, keputusan ujian Levene's $[F(1,109)=0.62, p=0.43]$ dalam kajian ini menunjukkan bahawa nilai varians dalam kumpulan eksperimen dan kawalan adalah sama dan data kajian ini mematuhi syarat ujian ANCOVA Satu Hala. Keputusan ujian ANCOVA Satu Hala pada Jadual 2 menunjukkan bahawa ujian pra sebagai variabel kawalan tidak memberikan kesan utama kepada kemahiran pemikiran sejarah $\left[F(1,108)=0.31, p=0.86, \eta^{2}=0.00\right]$ dan terdapat kesan utama kaedah pengajaran yang signifikan terhadap kemahiran pemikiran sejarah $\left[F(1,108)=30.21, p=0.00, \eta^{2}=0.22\right]$. Oleh itu, hipotesis nol $\left(\mathrm{H}_{\mathrm{ol}}\right)$ telah berjaya ditolak dan didapati bahawa terdapat perbezaan yang signifikan min skor kemahiran pemikiran sejarah bagi murid dalam kumpulan eksperimen berbanding dengan murid dalam kumpulan kawalan dengan mengawal min skor ujian pra.

Jadual 1: $\quad$ Statistik Deskriptif

\begin{tabular}{lcc}
\hline & $\begin{array}{c}\text { Kumpulan eksperimen } \\
(\mathbf{N}=\mathbf{5 5})\end{array}$ & $\begin{array}{c}\text { Kumpulan kawalan } \\
(\mathbf{N}=\mathbf{5 6})\end{array}$ \\
\hline Min & 125.05 & 103.84 \\
Sisihan Piawai & 18.85 & 21.43 \\
\hline
\end{tabular}


Malaysian Journal of Social Sciences and Humanities (MJSSH), Volume 5, Issue 2, (page 116 - 123), 2020

DOI: https://doi.org/10.47405/mjssh.v5i2.413

Jadual 2: Keputusan Ujian Kesan Variabel Antara Subjek

\begin{tabular}{lcccccc}
\hline \multicolumn{1}{c}{ Sumber } & $\begin{array}{c}\text { Jumlah } \\
\text { kuasa Dua } \\
\text { Jenis III }\end{array}$ & df & $\begin{array}{c}\text { Min } \\
\text { Kuasa } \\
\text { Dua }\end{array}$ & $\boldsymbol{F}$ & Sig & $\begin{array}{c}\text { Separa Eta } \\
\text { Kuasa Dua }\end{array}$ \\
\hline Model diperbetulkan & 12501.80 & 2 & 6250.89 & 15.20 & 0.00 & 0.22 \\
Pintasan & 151518.00 & 1 & 151518.00 & 368.31 & 0.00 & 0.77 \\
Ujian pra & 12.88 & 1 & 12.88 & 0.03 & 0.86 & 0.00 \\
Kumpulan & 12426.63 & 1 & 12426.63 & 30.21 & 0.00 & 0.22 \\
Ralat & 44429.51 & 108 & 411.38 & & & \\
Jumlah & 1508393 & 111 & & & & \\
Jumlah diperbetulkan & 56931.30 & 110 & & & & \\
\hline
\end{tabular}

$R$ Squared $=0.22$ (Adjusted $R$ Squared $=0.21)$

\section{Perbezaan min skor kemahiran memahami kronologi, kemahiran meneroka bukti, kemahiran membuat interpretasi, kemahiran membuat imaginasi dan kemahiran membuat rasionalisasi}

Berdasarkan analisis statistik deskriptif pada Jadual 3, min skor kemahiran memahami kronologi dalam kumpulan eksperimen adalah lebih tinggi $(M=3.61, S D=0.71)$ berbanding dengan kumpulan kawalan $(M=2.99, S D=1.06)$. Bagi min skor kemahiran meneroka bukti pula, kumpulan eksperimen adalah lebih tinggi $(M=3.51, S D=0.61)$ berbanding dengan kumpulan kawalan $(M=3.08, S D=0.79)$. Min skor kemahiran membuat interpretasi dalam kumpulan eksperimen adalah lebih tinggi $(M=3.52, S D=0.59)$ berbanding dengan kumpulan kawalan $(M=2.83, S D=0.66)$. Min skor kemahiran membuat imaginasi dalam kumpulan eksperimen adalah lebih tinggi $(M=3.67, S D=0.67)$ berbanding dengan kumpulan kawalan $(M=3.27, S D=0.79)$. Seterusnya, min skor kemahiran membuat rasionalisasi dalam kumpulan eksperimen adalah lebih tinggi $(M=3.55, S D=0.67)$ berbanding dengan kumpulan kawalan $(M=2.66$, $S D=0.67)$. Secara keseluruhannya, min skor bagi kesemua konstruk dalam kemahiran pemikiran sejarah iaitu kemahiran memahami kronologi, kemahiran meneroka bukti, kemahiran membuat interpretasi, kemahiran membuat imaginasi dan kemahiran membuat rasionalisasi adalah lebih tinggi dalam kumpulan eksperimen berbanding dengan kumpulan kawalan dalam kajian ini.

Jadual 3: Statistik Deskriptif

\begin{tabular}{lcccc}
\hline & \multicolumn{2}{c}{ Kumpulan eksperimen (N=55) } & \multicolumn{2}{c}{ Kumpulan kawalan (N=56) } \\
\cline { 2 - 5 } & Min & $\begin{array}{c}\text { Sisihan } \\
\text { Piawai }\end{array}$ & Min & $\begin{array}{c}\text { Sisihan } \\
\text { Piawai }\end{array}$ \\
\hline Memahami kronologi & 3.61 & 0.71 & 2.99 & 1.06 \\
Meneroka bukti & 3.51 & 0.61 & 3.08 & 0.79 \\
Membuat interpretasi & 3.52 & 0.59 & 2.83 & 0.66 \\
Membuat imaginasi & 3.67 & 0.67 & 3.27 & 0.79 \\
Membuat rasionalisasi & 3.55 & 0.67 & 2.66 & 0.67 \\
\hline
\end{tabular}

Seterusnya, keputusan ujian Box's $[F(15,47802.21)=3.28, p=0.23]$ menunjukkan bahawa nilai varians dalam kumpulan eksperimen dan kawalan adalah sama dan data kajian ini mematuhi syarat ujian MANCOVA Satu Hala. Berdasarkan Jadual 4, ujian multivariate Pillai's Trace menunjukkan bahawa tidak terdapat kesan variabel kawalan (ujian pra) yang signifikan $\left[F(5,104)=0.39, p=0.86, \eta^{2}=0.02\right]$. Tambahan pula, terdapat kesan utama kumpulan pengajaran yang signifikan $[F(5,104)=10.25, p=0.00$, $\left.\eta^{2}=0.33\right]$ terhadap variabel bersandar iaitu kemahiran memahami kronologi, kemahiran meneroka bukti, kemahiran membuat interpretasi, kemahiran membuat imaginasi dan kemahiran membuat rasionalisasi dalam kajian ini. Secara keseluruhannya, keputusan ini menunjukkan dengan mengawal variabel kawalan iaitu ujian pra, kumpulan pengajaran merupakan faktor yang memberi kesan kepada min skor kemahiran memahami kronologi, kemahiran meneroka bukti, kemahiran membuat interpretasi, kemahiran membuat imaginasi dan kemahiran membuat rasionalisasi dalam kalangan murid. Maka, hipotesis nol $\left(\mathrm{H}_{02}\right)$ berjaya ditolak dan didapati bahawa terdapat perbezaan yang signifikan dalam min skor kemahiran memahami kronologi, kemahiran meneroka bukti, kemahiran 
DOI: https://doi.org/10.47405/mjssh.v5i2.413

membuat interpretasi, kemahiran membuat imaginasi dan kemahiran membuat rasionalisasi bagi murid dalam kumpulan eksperimen dengan murid dalam kumpulan kawalan dengan mengawal min skor ujian pra.

Jadual 4: Ujian Multivariate

\begin{tabular}{llcccccc}
\hline Kesan & Nilai & $\boldsymbol{F}$ & $\begin{array}{c}\text { Hipotesis } \\
\text { df }\end{array}$ & $\begin{array}{c}\text { Ralat } \\
\text { df }\end{array}$ & $\begin{array}{c}\text { Sig. } \\
\text { Separa } \\
\text { Eta Kuasa } \\
\text { Dua }\end{array}$ \\
\hline Pintasan & Pillai's Trace & 0.78 & 75.71 & 5.00 & 104.00 & 0.00 & 0.78 \\
\hline Ujian Pra & Pillai's Trace & 0.02 & 0.39 & 5.00 & 104.00 & 0.86 & 0.02 \\
\hline Kumpulan & Pillai's Trace & 0.33 & 10.25 & 5.00 & 104.00 & 0.00 & 0.33 \\
\hline
\end{tabular}

Jadual 5: Ujian Kesan Antara Subjek

\begin{tabular}{|c|c|c|c|c|c|c|c|}
\hline Sumber & $\begin{array}{l}\text { Variabel } \\
\text { bersandar }\end{array}$ & $\begin{array}{c}\text { Jumlah } \\
\text { Kuasa } \\
\text { dua Jenis } \\
\text { III } \\
\end{array}$ & df & $\begin{array}{c}\text { Kuasa } \\
\text { Dua } \\
\text { Min }\end{array}$ & $F$ & Sig. & $\begin{array}{c}\text { Separa } \\
\text { Eta } \\
\text { Kuasa } \\
\text { Dua } \\
\end{array}$ \\
\hline \multirow{5}{*}{$\begin{array}{l}\text { Model yang } \\
\text { diperbetulkan }\end{array}$} & Kronologi & 10.56 & 2 & 5.28 & 6.37 & 0.00 & 0.11 \\
\hline & Bukti & 5.15 & 2 & 2.57 & 5.17 & 0.01 & 0.09 \\
\hline & Interpretasi & 13.27 & 2 & 6.63 & 16.74 & 0.00 & 0.24 \\
\hline & Imaginasi & 4.55 & 2 & 2.27 & 4.15 & 0.02 & 0.07 \\
\hline & Rasionalisasi & 22.40 & 2 & 11.20 & 24.94 & 0.00 & 0.32 \\
\hline \multirow[t]{5}{*}{ Pintasan } & Kronologi & 119.17 & 1 & 119.17 & 143.69 & 0.00 & 0.57 \\
\hline & Bukti & 120.99 & 1 & 120.99 & 242.88 & 0.00 & 0.69 \\
\hline & Interpretasi & 118.65 & 1 & 118.65 & 299.35 & 0.00 & 0.74 \\
\hline & Imaginasi & 137.03 & 1 & 137.03 & 249.75 & 0.00 & 0.70 \\
\hline & Rasionalisasi & 123.05 & 1 & 123.05 & 274.01 & 0.00 & 0.72 \\
\hline \multirow[t]{5}{*}{ Ujian Pra } & Kronologi & 0.05 & 1 & 0.05 & 0.06 & 0.81 & 0.00 \\
\hline & Bukti & 0.02 & 1 & 0.02 & 0.03 & 0.86 & 0.00 \\
\hline & Interpretasi & 0.04 & 1 & 0.04 & 0.10 & 0.75 & 0.00 \\
\hline & Imaginasi & 0.03 & 1 & 0.03 & 0.07 & 0.99 & 0.00 \\
\hline & Rasionalisasi & 0.42 & 1 & 0.42 & 0.93 & 0.34 & 0.01 \\
\hline \multirow[t]{5}{*}{ Kumpulan } & Kronologi & 10.55 & 1 & 10.55 & 12.73 & 0.00 & 0.11 \\
\hline & Bukti & 5.15 & 1 & 5.15 & 10.33 & 0.00 & 0.09 \\
\hline & Interpretasi & 13.13 & 1 & 13.13 & 33.13 & 0.00 & 024 \\
\hline & Imaginasi & 4.54 & 1 & 4.54 & 8.27 & 0.01 & 0.07 \\
\hline & Rasionalisasi & 21.66 & 1 & 21.66 & 48.23 & 0.00 & 0.31 \\
\hline \multirow[t]{5}{*}{ Ralat } & Kronologi & 89.57 & 108 & 0.83 & & & \\
\hline & Bukti & 53.80 & 108 & 0.50 & & & \\
\hline & Interpretasi & 42.81 & 108 & 0.40 & & & \\
\hline & Imaginasi & 59.25 & 108 & 0.55 & & & \\
\hline & Rasionalisasi & 48.50 & 108 & 0.45 & & & \\
\hline \multirow[t]{5}{*}{ Jumlah } & Kronologi & 1306.94 & 111 & & & & \\
\hline & Bukti & 1263.88 & 111 & & & & \\
\hline & Interpretasi & 1172.33 & 111 & & & & \\
\hline & Imaginasi & 1299.16 & 111 & & & & \\
\hline & Rasionalisasi & 1140.53 & 111 & & & & \\
\hline Jumlah yang & Kronologi & 100.13 & 110 & & & & \\
\hline \multirow[t]{4}{*}{ Diperbetulkan } & Bukti & 58.95 & 110 & & & & \\
\hline & Interpretasi & 56.07 & 110 & & & & \\
\hline & Imaginasi & 63.80 & 110 & & & & \\
\hline & Rasionalisasi & 70.90 & 110 & & & & \\
\hline
\end{tabular}


${ }^{\mathrm{b}}$. $R$ Squared $=0.09$ (Adjusted $R$ Squared $=0.70$ )

'. $R$ Squared $=0.24$ (Adjusted $R$ Squared $=0.22$ )

d. $R$ Squared $=0.07$ (Adjusted $R$ Squared $=0.05)$

'. $R$ Squared $=0.32$ (Adjusted $R$ Squared $=0.30$ )

Keputusan ujian kesan antara subjek pada Jadual 5 telah menunjukkan bahawa secara signifikan terdapat kesan kumpulan pengajaran terhadap kelima-lima variabel bersandar dalam kajian ini iaitu kemahiran memahami kronologi $\left[F(1,108)=12.73, p=0.00, \eta^{2}=0.11\right]$, kemahiran meneroka bukti $[F$ $\left.(1,108)=10.33, p=0.00, \eta^{2}=0.09\right]$, kemahiran membuat interpretasi $\left[F(1,108)=33.13, p=0.00, \eta^{2}=0.24\right]$, kemahiran membuat imaginasi $\left[F(1,108)=8.27, p=0.01, \eta^{2}=0.07\right]$ dan kemahiran membuat rasionalisasi $\left[F(1,108)=48.23, p=0.00, \eta^{2}=0.31\right]$. Keputusan analisis inferensi ini juga menunjukkan bahawa kumpulan pengajaran menyumbang sebanyak 11 peratus perubahan dalam kemahiran memahami kronologi, sebanyak 9 peratus perubahan dalam kemahiran meneroka bukti, sebanyak 24 peratus perubahan dalam kemahiran membuat interpretasi, sebanyak 7 peratus perubahan dalam kemahiran membuat imaginasi dan sebanyak 32 peratus perubahan dalam kemahiran membuat rasionalisasi. Maka, dapat dirumuskan bahawa kaedah pengajaran menyumbang paling tinggi dalam kemahiran membuat rasionalisasi dan kemahiran membuat interpretasi berbanding dengan kemahiran membuat kronologi, kemahiran meneroka bukti dan kemahiran membuat imaginasi.

\section{Perbincangan Kajian}

Dapatan kajian ini yang telah melaporkan bahawa terdapat perbezaan min skor yang signifikan bagi kemahiran pemikiran sejarah antara kumpulan eksperimen dan kawalan adalah disebabkan oleh penggunaan sumber dokumen dapat merangsang proses pemikiran kognitif aras tinggi melalui analisis sumber. Hal ini kerana perancangan dan pelaksanaan penggunaan sumber dokumen dalam kumpulan eksperimen secara teratur dan sistematik dengan memberikan perhatian khusus terhadap aspek pemilihan jenis sumber yang relevan, pemerolehan pengetahuan baharu yang dapat dikaitkan dengan pengetahuan sedia ada, peramalan sebab dan kesan berlakunya sesuatu peristiwa sejarah dapat ditentukan, menggalakkan motivasi dalam membuat pengkajian sejarah dan membuat kesimpulan terhadap sesuatu pentafsiran sejarah berdasarkan sokongan bahan bukti yang sahih (Havekes, Aardema \&Vries, 2010; Hartmann \& Hasselhorn, 2008; Martin, 2012; Nye, Hughes-Warrington, Roe, Russell, Deacon, \& Kiem, 2011). Peningkatan kemahiran pemikiran sejarah yang dilaporkan dalam kajian ini adalah disebabkan oleh kewujudan suasana pembelajaran sejarah yang bersifat kondusif yang membolehkan murid-murid beranggapan sebagai seorang ahli sejarah semasa membuat analisis sejarah (Claravall, 2017; Culminas-Colis \& Reyes, 2016; Spoehr \& Spoehr, 1994).

Tambahan pula, penggunaan sumber dokumen dalam proses pengajaran dan pembelajaran sejarah dapat memastikan murid-murid sentiasa berfokus semasa menganalisis dan memproses kandungan sumber-sumber teks bagi menjana proses pemahaman dan pemikiran yang mendalam (Barton, 2005; Cowgill II \& Waring, 2017; Nokes, 2014; Patterson, Lucas \& Kithinji, 2012; Reisman, 2012; Woyshner, 2010). Natijahnya, penggunaan sumber dokumen telah dibuktikan dapat meningkatkan kemahiran pemikiran sejarah yang terdiri daripada konstruk memahami kronologi, meneroka bukti, membuat interpretasi, membuat imaginasi dan membuat rasionalisasi dan dapatan kajian ini telah memberikan implikasi bahawa penggunaan sumber dokumen dalam proses pengajaran dan pembelajaran sejarah adalah berteraskan kepada proses pembinaan maklumat dan berupaya untuk meningkatkan pemikiran dengan lebih kritis dan analitis (Paul, Cerdan, Rouet \& Stadler, 2018; Bickford III, 2010; Hammar-lund, 2011; Gruber, 2017; Wineburg \& Martin, 2004). Hal ini kerana pengaplikasian dan penjanaan kemahiran pemikiran sejarah melalui penggunaan sumber dokumen telah membolehkan murid-murid dapat memahami sesuatu peristiwa masa lalu dengan pelbagai perspektif secara mendalam dengan meletakkan diri mereka secara imaginatif dalam situasi seseorang tokoh dan peristiwa, di samping mereka juga dapat melihat sesuatu peristiwa sejarah secara empati bagi membina corak pemikiran yang lebih terbuka, tolenrasi dan matang ke arah melahirkan warganegara yang mencintai negara (PPK, 2018). 


\section{Kesimpulan}

Kesimpulannya, penggunaan sumber dokumen merupakan suatu kaedah pengajaran dan pembelajaran sejarah yang dapat meningkatkan kemahiran pemikiran sejarah seperti yang disarankan dalam kurikulum sejarah yang bermatlamat untuk melengkapkan murid-murid dengan pelbagai pengetahuan kemahiran, nilai dan sikap yang merupakan asas kepada penjanaan proses berfikir aras tinggi.

\section{Rujukan}

Barton, K.C. (2005). Primary sources in history: Breaking through the myths. Phi Delta Kappan, $86(10), 745-753$.

Barton, K.C. (2018). Historical sources in the classroom: Purpose and use. HSSE Online, 7(2), 1-11.

Bickford III, J.H. (2010). Complicating students' historical thinking through primary sources reinvention. Social Studies Research \& Practices, 5(2), 47-60.

Claravall, E.B. (2017, Julai/Ogos). Thinking like a historian: Developing disciplinary literacy in history among middle school struggling readers. Literacy Today, 32-33.

Cook, T.D., \& Campbell, D.T. (1979). Quasi-experimentation: design and Analysis Issues for Field Settings. Chicago: Rand Mcnally.

Cowgill II, D.A., \& Waring, S.M. (2017). Historical thinking: An evaluation of student and teacher ability to analyze sources. Journal of Social Studies Education Research, 8(1), 115-145.

Cuban, L. (2016). Teaching history then and now: A story of stability and change in schools. Cambridge: Havard Education Press.

Culminas-Colis, M.V., \& Reyes, W.M. (2016). Teaching historical thinking skills through "reading like a historian" method. The Normal Light, 10(1), 56-77.

Fitzgerald, J.C. (2009). Textbooks and primary source analysis. Social Studies Research and Practice, $4(8), 37-43$.

Gleeson, A.M., D'Souza, L.A. (2016). Reframing a social studies methods course: Preparing elementary teacher candidates for the common core. The Social Studies, 107(5), 165-170.

Gruber, G. (2017). Teaching issues of contemporary history using historical sources and modern teaching methods. MATEC Web of Conferences, 121, 1-7.

Hammar-lund, K.G (2011). To know that or to know how? An attempt to integrate content and skills in history teaching. In K. Nordgren, P. Eliasson, \& C. Ronnqvist (Eds.), The processes of history teaching: An international symposium held at Malmo University, Swedan (pp.132-140). Karlstad: Karlstad University Press.

Hartmann, U., \& Hasselhorn, M. (2008). Historical perspective taking: A standardized measure for an aspect of student's historical thinking. Learning and Individual Differences, 18, 264-276.

Havekes, H., Aardema, A., \& Vries, J.D. (2010). Active historical thinking: Designing learning activities to stimulate domain-specific thinking. Teaching History, 139, 52-59.

Kementerian Pendidikan Malaysia. (2013). Pelan Pembangunan Pendidikan Malaysia 2013-2025. Putrajaya: Kementerian Pendidikan Malaysia.

Kobrin, D. (1996). Beyond the textbook: Teaching history using documents and primary sources. Portsmouth, New Hampshire: Heinemann.

Martin, D. (2012). Using core historical thinking concepts in an elementary history method course. The History Teacher, 45(4), 581-602.

Mohamad Rodzi Abdul Razak. (2009). Pembinaan negara bangsa Malaysia: Peranan pendidikan sejarah dan dasar pendidikan kebangsaan. JEBAT: Malaysian Journal of History, Polities \& Strategy, 36, 90-106.

Mohd Samsudin \& Shahizan Shaharuddin. (2012). Pendidikan dan pengajaran mata pelajaran sejarah di sekolah di Malaysia. JEBAT: Malaysian Journal of History, Polities \& Strategy, 39(2), 116141 .

Newmann, M. (2001). Primary Sources in perspective. Journal Educations and Students with Library of Congress Resources, 1-10.

Nokes, J.D. (2014). Elementary students' roles and epistemic stances during document based history lessons. Theory \& Research in Social Education, 42, 375-413.

Nunnally, J.C. (1978). Psychometrie Theory ( $2^{\text {nd }}$ Ed). New York: McGraw Hill. 
Nye, A., Hughes-Warrington, M., Roe, J., Russell, P., Deacon, D., \& Kiem, P. (2011). Exploring historical thinking and agency with undergraduate history students. Studies in higher Education, 36(7), 763-780.

Omardin Haji Ashaari \& Yunus Muhammad. (1996). Kaedah Pengajaran Sejarah. Kuala Lumpur: Utusan Publication and Distributor Sdn Bhd

Patterson, N.C., Lucas, A.G., \& Kithinji, M. (2012). Higher order thinking in social studies: An analysis of primary source document use. Social Studies Research and Practice, 7(2), 68-85.

Paul, J., Cerdan, R., Rouet, J.F., \& Stadtler, M. (2018). Exploring fourth grader' sourcing skills. Journal for the Study of Education and Development, 41(3), 536-580.

Pusat Perkembangan Kurikulum. (2014). Elemen KBAT dalam sumber. Putrajaya: Kementerian Pendidikan Malaysia.

Pusat Perkembangan Kurikulum. (2018). Dokumen standard kurikulum dan pentaksiran tingkatan 4 dan 5. Putrajaya: Kementerian Pendidikan Malaysia.

Reisman, A. (2012). The "document-based lesson": Bringing disciplinary inquiry into high school history classrooms with adolescent struggling readers. Journal of Curriculum Studies, 44(2), 233264.

Sandwell, R.M. (2008). Using primary documents in social studies and history. The Anthology of Social Studies: Issues and Strategies for Secondary Teacher, 2, 295-307.

Spoehr, K.T., \& Spoehr, L.W. (1994). Learning to think historically. Educational Psychologist, 29(2), 71-77.

Wineburg, S., \& Martin, D. (2004). Reading and rewriting history. Teaching for Meaning, 62(1), 4245.

Woyshner, C. (2010). Inquiry teaching with primary source documents: An iterative approach. Social Studies Research and Practice, 5(3), 36-45. 